\title{
Instrumentation for the surface measurements of atmospheric electrical parameters at Maitri, Antarctica: First results
}

\author{
C. Panneerselvam ${ }^{1 *}$, C. P. Anil Kumar ${ }^{1}$, Ajay Dhar ${ }^{2}$, K. U. Nair ${ }^{1}$, C. Selvaraj ${ }^{1}$, S. Gurubaran ${ }^{1}$, and B. M. Pathan ${ }^{2}$ \\ ${ }^{1}$ Equatorial Geophysical Research Laboratory, Indian Institute of Geomagnetism, Krishnapuram, Tirunelveli 627 011, India \\ ${ }^{2}$ Indian Institute of Geomagnetism, New Panvel, Navi Mumbai, India
}

(Received May 24, 2009; Revised March 11, 2010; Accepted June 4, 2010; Online published August 6, 2010)

\begin{abstract}
We are operating atmospheric electrical instruments like long wire antenna, electric eld meter, wire antenna and passive antenna for atmospheric Maxwell current, electric eld, conduction current and atmospheric potential gradient. This year (December 2008) we have installed Electric Field Meter (EFM-100) and wire antenna for measuring the atmospheric electric eld and conduction current. This instrument is deployed at Maitri, Antarctica and will be operated under any weather conditions like snow fall and strong blizzard etc. The study have been carried out during austral summer for the period of 2008 and 2009 at the Indian station, Maitri $\left(70.75^{\circ} \mathrm{S}, 11.75^{\circ} \mathrm{E}\right.$, $117 \mathrm{~m}$ above mean sea level). The present work has been to understand the new instrument system in response to different meteorological conditions and on fairweather days. In this paper we have selected the data of the days during magnetically quiet period to minimize the upper atmospheric contribution. Fairweather' conditions, i.e., days with absence of high winds, drifting or falling snow and clouds. The diurnal variation curve of electric eld during fairweather days is a single periodic with a minimum at 04:00 UT and a maximum at 19:00 UT. But atmospheric current variation has minimum 03:00 UT for Maxwell current and conduction current. The maximum for Maxwell current is at 20:00 UT and 19:00 UT for the conduction current, which is very similar to the Carnegie curve. The measured electric eld from the Passive antenna and EFM-100 compared and is behaving similar variation. Using Maxwell current density and conduction current density we have separated the displacement current density.
\end{abstract}

Key words: Conduction current, electric eld, Maxwell current, fairweather day, global electric circuit, displacement current.

\section{Introduction}

The global electrical circuit (GEC) is a large scale current system, formed by an aggregate of geophysical shells and electrical sources. Consequently, the GEC has the properties determinable by physical state of the magnetosphere, ionosphere, atmosphere and lithosphere. Atmospheric electricity is an integral part of the global electrical circuit. In this way, the global thunderstorm activity is able to maintain a time varying electric potential difference of $\sim 300 \mathrm{kV}$, directed downward between the equipotential surfaces of the ionosphere and the ground (Adlerman and Williams, 1996). The variations of vertical electric eld and current are direct evidence for GEC action. The periodic electric eld variations, measured by Carnegie expedition over ocean, are considered as display of worldwide thunderstorm activity and are the classical standard of electrical global variations. The study of global electric circuit (GEC) can help in understanding the electrical environment of the earth's

*Present address: Geomagnetic Laboratory, Winter Member of 28th Indian Scienti c Antarctica Expedition to Antarctica, Maitri, Antarctica (November 2008-February 2010).

Copyright (c) The Society of Geomagnetism and Earth, Planetary and Space Sciences (SGEPSS); The Seismological Society of Japan; The Volcanological Society of Japan; The Geodetic Society of Japan; The Japanese Society for Planetary Sciences; TERRAPUB.

doi:10.5047/eps.2010.06.001 atmosphere. This approach can provide a good framework for exploring interconnections and coupling of various regions of the atmosphere (Rycroft, 2006). The measuring site needs to be free of atmospheric aerosols and convective activity, otherwise these would obscure the weak signatures representing the global thunderstorm activity (Israel, 1973). Measurements from Antarctica also allow us to investigate meteorological effects, such as blizzards, wind turbulence, snowfall and clouds, on local electrical processes and enable us to understand the electrical climate of the Antarctic plateau (Cobb, 1977).

The global circuit involves lower atmosphere generators and upper atmosphere generators, the latter being signi cant over the polar caps. The Antarctic plateau supports a desert-like climate with clear skies and very low atmospheric aerosol content (Tinsley and Zhou, 2006). In summer, the prevailing winds are light, moving in a nearly constant direction and the atmosphere is relatively free of turbulent and convective motions (Byrne et al., 1993). The downward air-Earth current being delivered to the surface of the Antarctic plateau is larger than the global average owing to its location in high latitudes. Therefore, because of its orography, the Antarctica plateau is strongly coupled to the GEC.

In this paper, we report observations of the atmospheric conduction current and electric eld made at Maitri for the summer of years 2008 and 2009. The results have been 
compared with the earlier observations made in Antarctica. A variety of scientific experiments involving Digital fluxgate magnetometer, proton precession magnetometer for detecting the earth's magnetic field, GPS for solid earth geomagnetic study and Riometer for $D$-region absorption studies, are being carried out by the Indian Institute of Geomagnetism, round the year. We have installed Electric field meter and wire antenna for the measurements of atmospheric electric field and conduction current density.

\section{Description of the Instruments}

The most widely used ground-based sensors for the air-Earth current measurements are: Wilson plate (Israel, 1973), the horizontal long-wire antenna (Ruhnke, 1969), horizontal passive antenna (Harrison, 1996) and spherical shell in the form of two hollow hemispheres (Burke and Few, 1978). The horizontal long wire antenna, if placed in the atmosphere, will closely follow the electrical current variations of the atmosphere after the initial net charge on the antenna leaks off. When the antenna is shorted to the ground through a resistor, it will generate a voltage that is proportional to the air-Earth current. In the present experimental setup, a long wire of length $41.5 \mathrm{~m}$ and thickness $3 \mathrm{~mm}$ is kept horizontally stretched parallel to the ground at a height of $1.2 \mathrm{~m}$. The wire is mechanically supported by means of masts. By using teflon rods at their ends it is ensured that the antenna wire is electrically insulated from the supporting masts. The input is fed through the electrometer (Model AD 549) that has high input impedance and permits extremely low input bias current (10-14 A). The electrometer measures the current up to $1 \mathrm{nA}$ (corresponding to the output voltages whose limit is $\pm 5 \mathrm{~V}$ ) with a feedback resistance of $5 \times 10^{9} \Omega$. A unity gain operational amplifier (LM308) amplifies the electrometer output signal. The amplified signal is then taken in a shielded cable over a distance of $10 \mathrm{~m}$ to the control room where it is fed to a PC-based data logger. The sensitivity of the digitized signal is $2.44 \mathrm{mV}$ that will correspond to a current of $0.5 \mathrm{pA}$. The data are recorded at a sampling interval of one second (Panneerselvam et al., 2003).

The atmospheric electric field has been measured with a horizontal passive wire antenna of $20 \mathrm{~m}$ in length and $3 \mathrm{~mm}$ in diameter made of tinned copper. The sensor is supported $1 \mathrm{~m}$ above the ground by means of masts. At each end there are porcelain egg insulators, and a PTFE (Poly Tetra Flouro Ethylene) or teflon insulator under steady compression at the masts shown in Fig. 1. The insulators are regularly cleaned with isopropanol. A guard potential, which is close to the potential on the wire, is applied to the support wires at each end. This is to minimize the leakage through the insulators, which would occur if the support were merely grounded. As a precaution against the guard potential influencing the potential sensed by the antenna, the parallel cable that carries the guard signal to the far end of the antenna has an earthed screen. The antenna makes contact with a short wire made of same material as that of the antenna, which is connected to a voltage follower electrometer (LMC 6042) with the unity gain that permits ultra low input bias current of nearly $1 \mathrm{fA}$. The amplified signals are filtered by the low pass filter at the input of data logger,

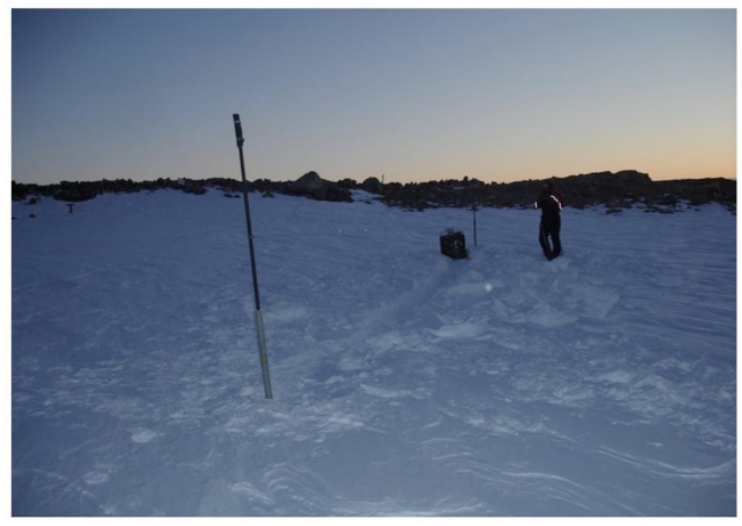

Fig. 1. Photograph of conduction current wire antenna at Maitri, Antarctica.

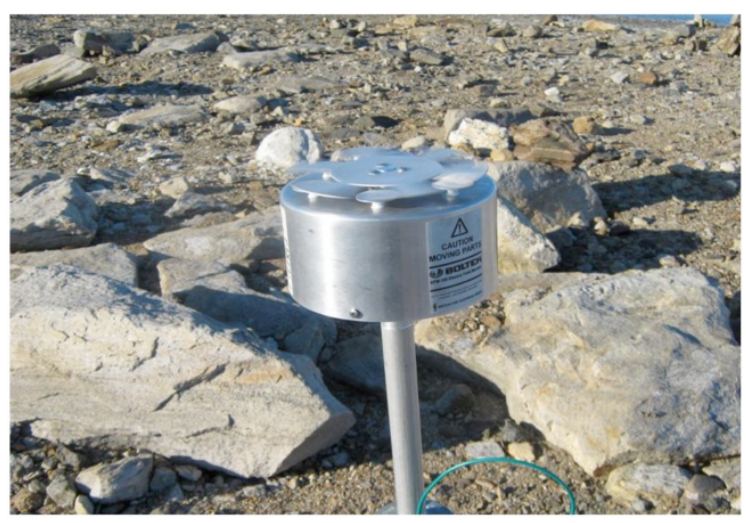

Fig. 2. Photograph of Electric Field Meter-100.

which is $50 \mathrm{~m}$ away from the preamplifier. The filtered signal is fed to the PC at a sampling interval of one second (Panneerselvam et al., 2007). This year we have installed Electric field meter (100) for the same atmospheric electric field measurements shown in Fig. 2. After comparison work the passive antenna system was stopped for keeping it as a standby. The details are available in info@boltek.com. The sampling interval of this instrument is 0.5 seconds. It can be operated in any weather conditions with $12 \mathrm{~V} \mathrm{DC}$.

The sources other than the air-Earth conduction current that contribute to the measured current density are (i) the convection current, (ii) the displacement current, (iii) the point discharge current, (iv) the precipitation current, and (v) the lightning current (Israel, 1973). The sum of all these currents is collectively called the Maxwell current. Out of these, the convection current arises when the charge carriers are moved by the winds, and hence it is a possible source for the locally induced component in the measured current. The lightning and precipitation currents are not considered since the datasets selected are during fairweather periods. The location of the experimental setup on a barren land does not favour point discharge current because the sharp edges provided by plants and trees allow for point-discharge currents but in Antarctica there are no trees and plants hence, contribution of point-discharge current is negligible. The effective area of the present experimental setup is $66.1 \mathrm{~m}^{2}$ calculated from the formula $S=h C / \varepsilon$ (Kasemir and Ruhnke, 
1959; Tammet et al., 1996; Panneerselvam et al., 2007), $\varepsilon$ being the dielectric constant of air, $C$ the capacity of the antenna and $h$ the height of the antenna above the ground. Here the value for $C=298.2 \mathrm{pF} ; h=2 \mathrm{~m}$. Capacity is measured with Digital multimeter as well as calculated using the formula for $C$ (Tammet et al., 1996). The total current density can be estimated by dividing the measured current by the effective area of the antenna.

\section{Site Description}

The Indian Antarctic station, Maitri is located in the Schirmacher oasis in the Dronning Maud Land, East Antarctica (117 m above the mean sea level). Antarctica has only around $2 \%$ of its area that is free from ice. The nearest steep cliff of the east-west trending glacier on the southern side of the station is more than $700 \mathrm{~m}$ away from the station and is $300 \mathrm{~m}$ in height. The snow-covered surface during summer season was more than half a kilometer away from the station. The instruments were installed on barren land near the station. The surface of the station area is mainly covered by sandy and loamy sand types of soil. The solar zenith angle at Maitri varies from $48^{\circ}$ to $88^{\circ}$ during summer months. There was no sunset till the third week of January, but periods of short nights slowly increased during February. The variations in surface meteorological parameters were measured by automatic weather station which is installed during this expedition. The cloud cover over the station occurs mainly under the in uence of subpolar low-pressure systems and shows an alternating sequence of the sky changing from overcast to clear as the system moves away (Deshpande and Kamra, 2001).

\section{Results and Discussion}

Measurements of atmospheric electric currents and Electric eld have been made at Maitri, Antarctica since 1999. This year we have installed EFM-100 and wire antenna for the measurements of electric eld and conduction current. The selection of the fairweather days the days with 24 hours clear sky with low wind speed, less than $5 \mathrm{~m} / \mathrm{s}$ wind speed has been made with the standard procedure adopted in the past (Reiter, 1985). In the present study, a set of days during which fairweather conditions prevailed all through the day were considered, and the hourly averages were computed to yield the diurnal variation. Features corresponding to the UT variation were then looked for. If thunderstorm activity was responsible for the generation of global electric circuit and its variation with time, one would expect in the average pattern a maximum in the measured electrical parameters near 19:00 UT and a minimum near 03:00 UT. To show the response of the sensors we have shown diurnal variation of the measured atmospheric electrical parameters as a raw data during fairweather condition as well as meteorologically disturbed day.

The diurnal variation of the hourly averaged values of the atmospheric electric eld and current density for the period of November 2008-February 2009 is depicted in Fig. 3. The diurnal variation of curve of electric eld during fairweather days has a single period with a minimum at 04:00 UT and a maximum at 19:00 UT. The atmospheric current variation has minimum 03:00 UT and has a maximum for Maxwell
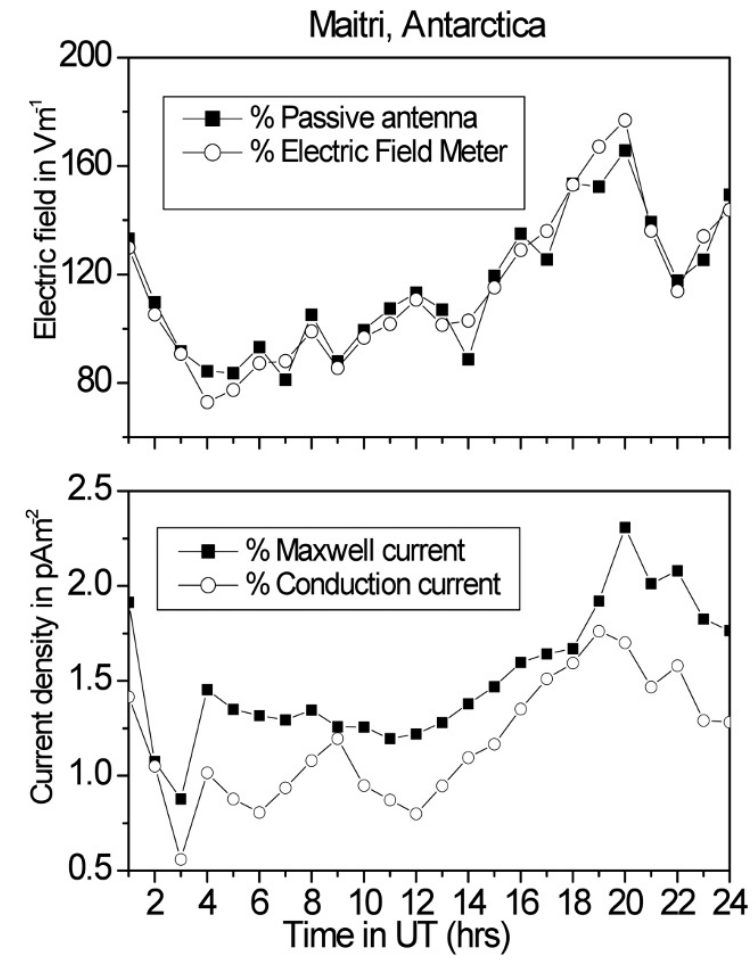

Fig. 3. Diurnal variation of atmospheric electric parameters during summer 2008/2009.

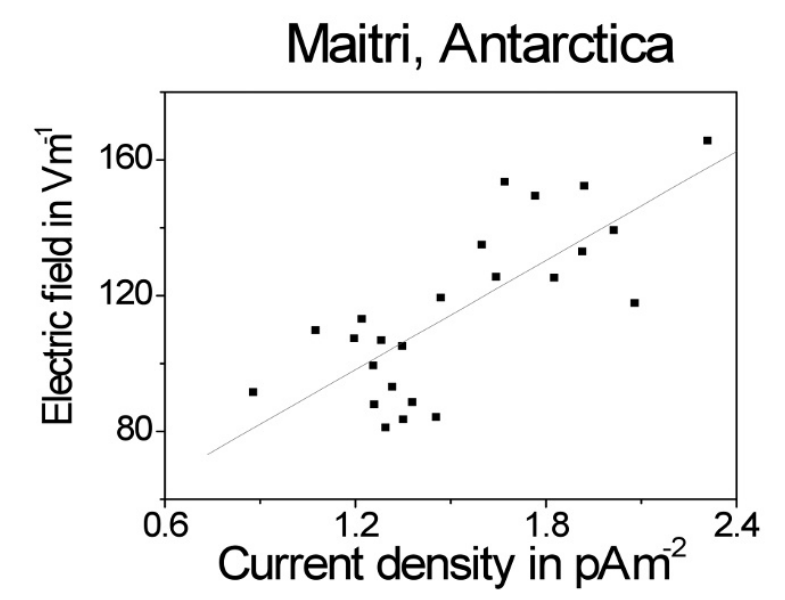

Fig. 4. Conduction current $V_{\mathrm{s}}$ electric eld during summer 2008/2009.

current at 20:00 UT and 19:00 UT for the conduction current, which is very similar to the Carnegie curve. This variation has been widely observed, and according to classical theory, it is generally attributed to the variation with time of day of the number of thunderstorms across the globe (Roble, 1985).

Part of the day-to-day variations may be ascribed to the solar wind/magnetospheric and ionospheric contribution because our station is outside the region of polar currents during the magnetically quiet conditions. Electric elds are generated in the ionosphere by the dynamo action and by the interaction of the magnetosphere with the solar wind and its frozen-in Interplanetary Magnetic Field (IMF). This part corresponds to mainly horizontal potentials of the order of tens of kilovolts. This horizontal poten- 
(a)

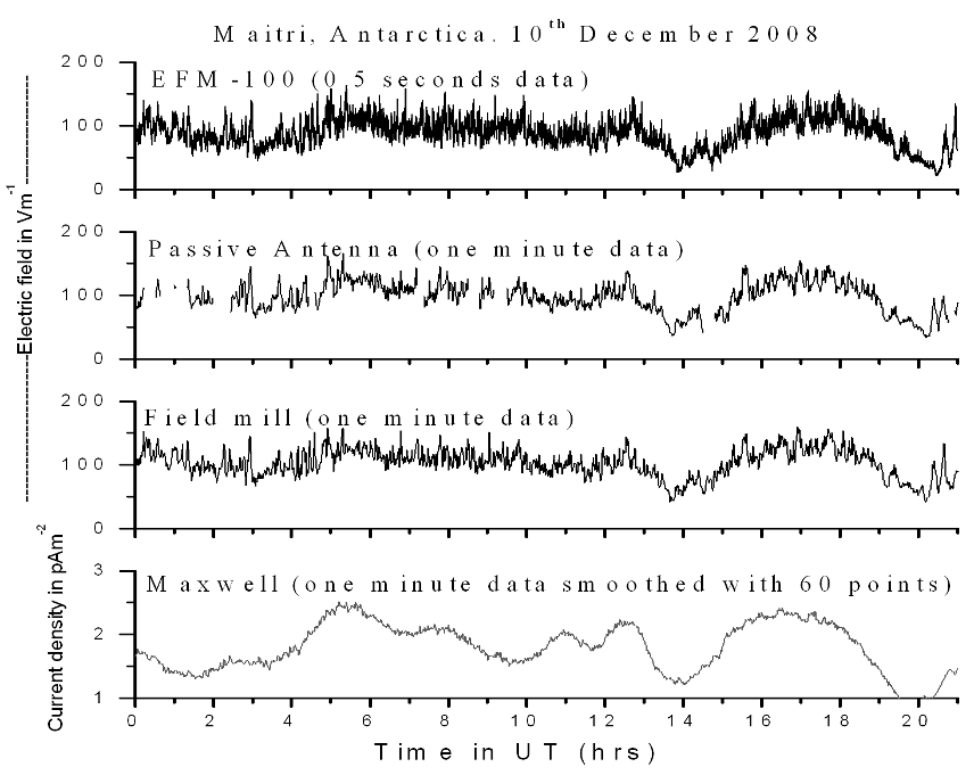

(b)

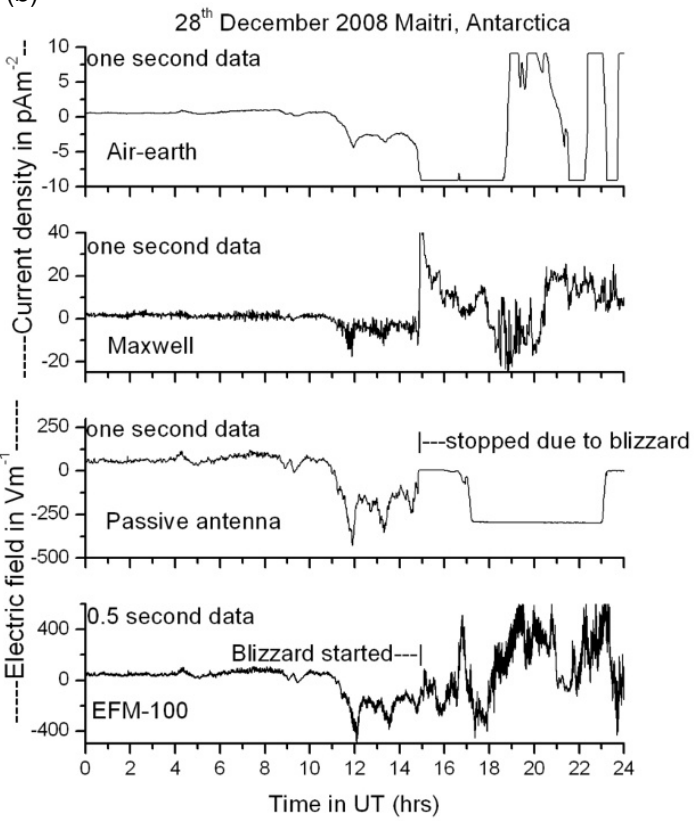

Fig. 5. (a) Diurnal variation of GEC parameters during clear sky day (raw data). (b) Same as (a) but in blizzard day.

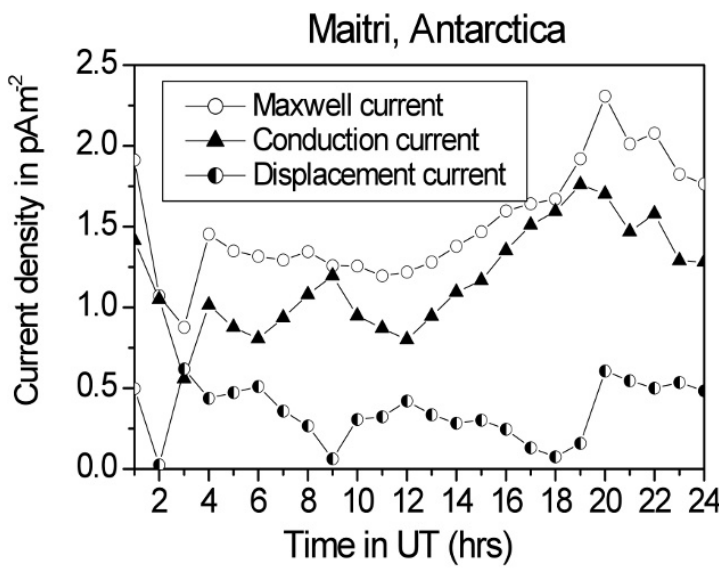

Fig. 6. Different currents during summer 2008/2009.

tial will have effect on the measured atmospheric electrical parameters. The observations made during the sunspot minimum period more are less no sunspot during this period, the details available in www.spaceweather.com. One would expect the upper atmospheric contribution less compared to active sunspot days. Further we have selected the days during magnetic quiet day to reduce upper atmospheric contribution the measured atmospheric electrical parameters.

Hourly average value of the measured current and electric field variations using wire antenna and Electric field meter are shown in Fig. 4. The correlation coefficient for these parameters more than 0.9 during fairweather days and hence, during fair weather the conductivity is more or less stable. During fairweather days the electric field and current variations are similar but during meteorologically disturbed days the variation of field and current always not similar because of atmospheric conductivity. During blizzard conditions due to high wind speed, falling and drifting snow brings different charges near to the sensor complex. And hence, the conductivity changes according to the polarity of the charged particles. Due to the change of the conductivity the current and field changes occur. In Fig. 5(a) and 5 (b). we have shown the diurnal variation of the field and current during fairweather day as well as meteorologically disturbed day.

From the measured Maxwell current density and conduction current density we have separated the displacement current density. Maxwell current measures conduction current and displacement current during fair weather condition. Subtracting the conduction current density from the Maxwell current density we will get the displacement current, which is shown in Fig. 6. During magnetic quiet period the upper atmospheric contribution to the measured Maxwell current is less compared with the magnetic disturbed days. Our observation made during sunspot zero days, fairweather and magnetic quiet day, and then also the measured Maxwell current has some displacement current. The measured Maxwell current follows the famous "Carnegie curve" which implies the measured Maxwell current at Maitri, Antarctica dominated by the thunderstorm activity during magnetic quiet days.

\section{Conclusion}

The variations of measured atmospheric electrical parameters are similar to the famous fairweather 'Carnegie curve' during fairweather days. And also the days were selected during magnetic quiet conditions. The upper atmospheric contribution to the measured electrical parameter is very low because the observation made during sunspot zero days, hence the measured the atmospheric electrical parameters are to the contribution of the global thunderstorm activity. The conductivity more or less stable during fairweather days and it is varying during meteorologically disturbed 
days. Detailed study about the upper atmospheric contribution will be carried out after reaching to the mainland. With the continuous measurements of atmospheric electrical parameters and geomagnetic eld variations, there is scope for addressing the problems related to the modulation of GEC by the in uence of magnetosphere-ionosphere-lower atmosphere coupling processes on the near-surface electrical parameters in the polar caps.

Acknowledgments. The author gratefully acknowledge M. J. Rycroft and another referee for their valuable remarks and corrections, which helped in making improvements on the original version. The author C. Panneerselvam, who is wintering at Maitri, Antarctica gratefully acknowledge his Director Prof. Archanna Bhattacharrya, who gave this opportunity to me to winter here, collect the data and also allowed me to publish the results. Secondly my thanks goes to my leader Dr. Pradip Malhotra. He is the rst Medical professional, who came as a leader and provided invaluable help during this work and my stay at Maitri. I would like to thank all other members who were wintering with me. They have provided me with high quality of support and help without which I could not have completed this work in polar cap. I would also like to thank the Director of National Center for Ocean and Antarctic Research, Goa, Shri. Rasik Ravindra and Logistic director Shri. Javed Beg for the support provided by them to me during this expedition. Finally The Ministry of Earth Science, Government of India, for conducting a variety of experiments at the Indian Antarctic station, Maitri, is gratefully acknowledged.

\section{References}

Adlerman, E. J. and E. R. Williams, Seasonal variation of the global electric circuit, J. Geophys. Res., 101, 29,679-29,688, 1996.

Burke, H. K. and A. A. Few, Direct measurements of the atmospheric conduction current, J. Geophys. Res., 83, 3093-3098, 1978.

Byrne, G. J., J. R. Benbrook, E. A. Bering, A. A. Few, G. A. Morris, W. J. Trabucco, and E. W. Paschal, Groun based instrumentation for measurements of atmospheric conduction current and electric eld at South pole, J. Geophys. Res., 98, 2611-2618, 1993.
Cobb, W. E., in Electrical Process in Atmospheres, edited by H. Dolezalek and R. Reiter, 161-167, Steinkopff, Darmstadt, 1977.

Deshpande, C. G. and A. K. Kamra, Diurnal variations of the atmospheric electric eld and conductivity at Maitri, Antarctica, J. Geophys. Res., 106, 14,207-14,218, 2001

Harrison, R. G., An atmospheric electrical voltmeter follower, Rev. Sci. Inst., 67(7), 2636-2638, 1996.

Israel, H., Atmospheric Electricity, vol. II, Isr. Program for Sci. Transl., Jerusalem, 1973.

Kasemir, H. W. and L. H. Ruhnke, Antenna problems of measurement of the air-Earth current, in Recent Advances in Atmospheric Electricity, edited by L. G. Smith, pp. 137-147, Pergamon, New York, 1959.

Panneerselvam, C., K. U. Nair, K. Jeeva, C. Selvaraj, S. Gurubaran, and R. Rajaram, A comparative study of atmospheric Maxwell current and electric eld from a low latitude station Tirunelveli, Earth Planets Space, 55, 697-703, 2003.

Panneerselvam, C., K. U. Nair, C. Selvaraj, K. Jeeva, C. P. Anil Kumar, and S. Gurubaran, Diurnal variation of Maxwell current over the lowlatitude continental station, Tirunelveli, India $\left(8.7^{\circ} \mathrm{N}, 77.8^{\circ} \mathrm{E}\right)$, Earth Planets Space, 59, 429-435, 2007.

Reiter, R., Fileds, Currents and Aerosols in the Lower Troposphere, published for the division of Atmospheric Sciences, National Science Foundation, Washington, D.C., by Amerind Publishing Co. Pvt. Ltd., New Delhi, 1985.

Roble, R. G., On solar-terrestrial relationships in atmospheric electricity, J. Geophys. Res., 90, 6000-6012, 1985.

Ruhnke, L. H., Area averaging of atmospheric electric currents, J. Geomag. Geoelectr., 21, 453-462, 1969.

Rycroft, M. J., Electrical processes coupling the atmosphere and ionosphere: An overview, J. Atmos. Sol.-Terr. Phys., 68, 445-456, 2006.

Tammet, H., S. Israelsson, E. Knudsen, and T. J. Tuomi, Effective area of a horizontal long-wire antenna collecting the atmospheric electric vertical current, J. Geophys. Res., 101, 29,671-29,677, 1996.

Tinsley, B. A. and L. Zhou, Initial results of a global circuit model with variable stratospheric and tropospheric aerosols, J. Geophys. Res., 111, D16205, 1-23, 2006.

C. Panneerselvam (e-mail: panneer.iig@gmail.com), C. P. Anil Kumar, Ajay Dhar, K. U. Nair, C. Selvaraj, S. Gurubaran, and B. M. Pathan 